\title{
Production of biosurfactant by Pseudomonas aeruginosa PB3A using agro- industrial wastes as a carbon source
}

\author{
Varadharajan Saravanan and Subramaniyan Vijayakumar* \\ Department of Botany and Microbiology, A.V.V.M. Sri Pushpam College, Thanjavur-613 503, Tamil Nadu, India. \\ Email: svijaya_kumar2579@rediff.com
}

Received 30 July 2013; Received in revised form 1 October 2013; Accepted 7 November 2013

\begin{abstract}
Aims: To evaluate Pseudomonas aeruginosa PB3A strain for the production of biosurfactant using agro-industrial waste as a carbon source.

Methodology and results: $P$. aeruginosa PB3A strain was isolated from oil contaminated soil and was found to be a potential biosurfactant producing microorganism based on the following screening methods; hemolytic activity, drop collapse test, emulsification activity and surface tension measurement. The identification of the isolate was confirmed by $16 \mathrm{~S}$ rRNA sequencing. The isolate exploited for the application of agro industrial wastes such as used castor oil, coconut oil, corn oil, motor oil, olive oil, olein, rapeseed oil, sunflower oil, barley bran, cassava flour waste, peanut cake, potato waste, rice bran and wheat bran for biosurfactant production by replacing the existing carbon source. Among the cheap substrates, both the used corn oil and cassava waste flour showed maximum productivity of $0.62 \mathrm{mg} / \mathrm{mL}$ and 0.60 $\mathrm{mg} / \mathrm{mL}$ respectively when cultivated independently in the MSM medium.

Conclusion, significance and impact study: Present study was aimed at the application of agro-industrial wastes for biosurfactant production. The study indicates that agro-industrial wastes can be used as inexpensive substrates by replacing synthetic media for the production of biosurfactant.
\end{abstract}

Keywords: Toxicity, agro-industrial wastes, biosurfactant, drop collapse, hemolytic assay, surface tension.

\section{INTRODUCTION}

Surfactant belongs to amphiphatic molecules, consisting of a hydrophobic and a hydrophilic group which helps in reducing the surface and interfacial tension in water/hydrocarbon systems (Prantera et al., 2002). The application of synthetic surfactants for the treatment of hydrocarbon-contaminated soil improves the restoration; however, they get accumulated in the ecological system leading to severe environmental damage. The biosurfactants or the surface active component synthesized by the microorganisms appears to be an excellent alternative approach for the synthetic surfactants. Besides possessing surface and emulsifying activities (Van Hamme et al., 2006; Singh et al., 2007) these bio surfactants exhibit antimicrobial and anti adhesive properties (Singh and Cameotra, 2004; Rodrigues et al., 2006). Microbial surfactants composed of diverse group of surface-active components are classified by their chemical composition and microbial origin which include lipopeptides, glycolipids, lipopolysaccharides, polysaccharide-protein complexes, protein-like substances, fatty acids, phospholipids, and neutral lipids (Van Hamme et al., 2006).

Distinct properties and physiological functions have been observed for different groups of biosurfactants produced by different microorganisms which include enhanced solubility of hydrophobic compounds, heavy metal binding, cell adhesion and aggregation, biofilm formation and quorum sensing (Ron and Rosenberg, 2001; Singh and Cameotra, 2004). Among the various microorganisms, bacteria are the important group of surfactant-producers although few yeasts and fungi are also reported (Desai and Banat, 1997). The most common biosurfactants are glycolipids and lipopeptides which include rhamnolipids synthesized by Pseudomonas aeruginosa (Nitschke et al., 2005), sophorolipids released by Candida species (Daverey and Pakshirajan, 2009), and surfactin and iturin synthesized by Bacillus subtilis strains (Ahimou et al., 2000).

In the present scenario, the major drawback that prevents the widespread use of microbial biosurfactants is the economic viability of the production costs. Currently various strategies have been evaluated in order to reduce the fermentation process economics and make it competitive with chemically synthesized surfactants (Makkar and Cameotra, 2002). Future research on biosurfactant has to be more focused on the economics of the fermentation processes, mainly through the usage of alternative low-cost production media (Makkar and Cameotra, 2002; Rodrigues and Teixeira, 2008).

\section{*Corresponding author}




\section{MATERIALS AND METHODS}

\section{Materials}

All the chemicals and reagents used in the present study were of analytical grade and purchased from SRL Chemicals and Merck Chemicals, India. Used residual oil wastes were collected from various shops and household; agro-wastes were collected from local market and industries from Chennai and nearby area.

\section{Isolation and screening of biosurfactant producers}

Bacterial strains used in this study were isolated from oil contaminated soils at Chennai as described by Saravanan and Vijayakumar (2012). The samples were serially diluted and preserved in nutrient agar slant for further screening of biosurfactant production. Hemolytic activity was performed as described by Carrillo et al., (1996) with slight modifications. Isolated bacterial strains were screened for their hemolytic activity on blood agar plates with 5 vol. \% of blood and incubated at $37^{\circ} \mathrm{C}$ for 24 h. The hemolytic activity was distinguished based on the presence of a clear zone around the colonies. Using a 96 micro-well plate the drop collapse test was carried out as described by Bodour and Maier (1998). Two microliter of crude oil was added to the well and left to equilibrate for $24 \mathrm{~h}$, followed by $5 \mu \mathrm{L}$ of $48 \mathrm{~h}$ cell free supernatant of bacterial strain and the drop size was observed after 1 min with the aid of a magnifying glass. Positive result shows a flat drop and rounded drops were scored as negative which indicate a negative result for biosurfactant production. The emulsifying activity of biosurfactant was carried out according to Cooper and Goldenberg (1987). After $48 \mathrm{~h}, 2 \mathrm{~mL}$ of cell free supernatant and hydrocarbon (oil) was taken in a test tube and vortexed at high speed for $1 \mathrm{~min}$ and left to stand for $24 \mathrm{~h}$. Emulsifying (E24) activity was expressed as the percentage of the total height occupied by the emulsion (Bodour et al., 2004). Surface tension (ST) was determined using a Kruss processor tensiometer by the plate method (Płaza et al., 2011). The bacterial cultures were cen $\neg$ trifuged at 10,000 rpm for $20 \mathrm{~min}$ and the cell free supernatant was analyzed for the determination of surface activity. All the assays were performed in triplicate with appropriate positive and negative controls.

\section{Identification of bacterial strain}

The selected isolate PB3A was identified by morphological and biochemical analysis based Bergey's Manual of Systemic Bacteriology (Holt et al., 1994). The identity of bacterial strain PB3A was further confirmed by $16 S$ rRNA gene sequence analysis. The total genomic DNA was extracted from an overnight culture in Luria Bertani broth using CTAB (Cetyltrimethylammonium Bromide) method (Ausubel et al., 1994). The 16S rRNA gene amplification was done by universal 16S rDNA primers 27f (5'- GAGTTTGATCCTGGCTCAG-3') and 1492r (5'-TACGGYTACCTTGTTACGACTT-3') followed by purification using QIAquick Gel Extraction kits from Qiagen. DNA sequencing was performed using DTS cycle sequencing kit and Applied Biosystems automated DNA sequencer (Marchesi et al., 1998). Nucleotide sequences were determined for both strands. Sequence obtained was aligned and used for similarity comparisons using the BLAST program (Altschul et al., 1990).

\section{Production of biosurfactant using agro-industrial wastes}

In the present study, various solid and liquid wastes were used as cheap substrates for biosurfactant production. Different waste substrates such as used castor oil, coconut oil, corn oil, motor oil, olive oil, olein, rapeseed oil, sunflower oil, barley bran, cassava flour waste, peanut cake, potato waste, rice bran and wheat bran were amended in MSM medium by replacing glucose at a concentration of $1 \%$ in the final composition according to Tahzibi et al. (2004) ( $\mathrm{g} / \mathrm{L}$ of distilled water: $\mathrm{NaNO}_{3}, 15$; $\mathrm{NaCl}, 1.1 ; \mathrm{KCl}, 1.1 ; \mathrm{KH}_{2} \mathrm{PO}_{4}, 3.4 ; \mathrm{K}_{2} \mathrm{HPO}_{4}, 4.4$; $\mathrm{MgSO}_{4} \cdot 7 \mathrm{H}_{2} \mathrm{O}, 0.5 ; \mathrm{FeSO}_{4} \cdot 7 \mathrm{H}_{2} \mathrm{O}, 0.00028$; yeast extract, 0.5 ; glucose $1 \%$ ). The selected strain PB3A was then inoculated into the medium amended with different wastes substrates and kept in shaker incubator (100 rpm) at $37^{\circ} \mathrm{C}$. After $48 \mathrm{~h}$ of incubation, cell-free supernatant was obtained by centrifuging the culture broth at 10,000 rpm for $20 \mathrm{~min}$. The biosurfactant concentration in the cell-free culture broth was estimated using orcinol assay method (Tuleva et al., 2002). One hundred microliter of each sample was mixed with $900 \mu \mathrm{L}$ of a $0.19 \%$ orcinol solution (in $53 \% \mathrm{H}_{2} \mathrm{SO}_{4}$ ) and heated at $80{ }^{\circ} \mathrm{C}$ for $30 \mathrm{~min}$. The samples were then cooled to room temperature and absorbance was measured at $421 \mathrm{~nm}$ and compared with the standard curve prepared with L-rhamnose and expressed as rhamnose equivalents (RE) $(\mathrm{mg} / \mathrm{mL})$.

\section{Statistical analysis}

The data represent the arithmetical averages of at least three replicates. The results were represented as mean value \pm standard deviation (SD). The statistical analysis was performed using MS office Excel 2007 for calculating mean, standard deviation and standard error.

\section{RESULTS AND DISCUSSIONS}

Various bacterial isolates obtained from oil contaminated soil were screened for the presence of biosurfactant activities using blood hemolytic test, drop collapse test, emulsification index (E24) and Surface tension according to Satpute et al. (2008) who described the significance of more than one screening method for the primary screening of potential biosurfactant producers. Among the different bacterial strain, PB3A showed hemolytic colonies (Figure 1) on blood agar which was similar to the report done by Mulligan et al. (1984). The strain also showed a flat drop appearance (Figure 2) in the drop collapse, a sensitive method to detect biosurfactant production as suggested by Jain et al. (1991). 


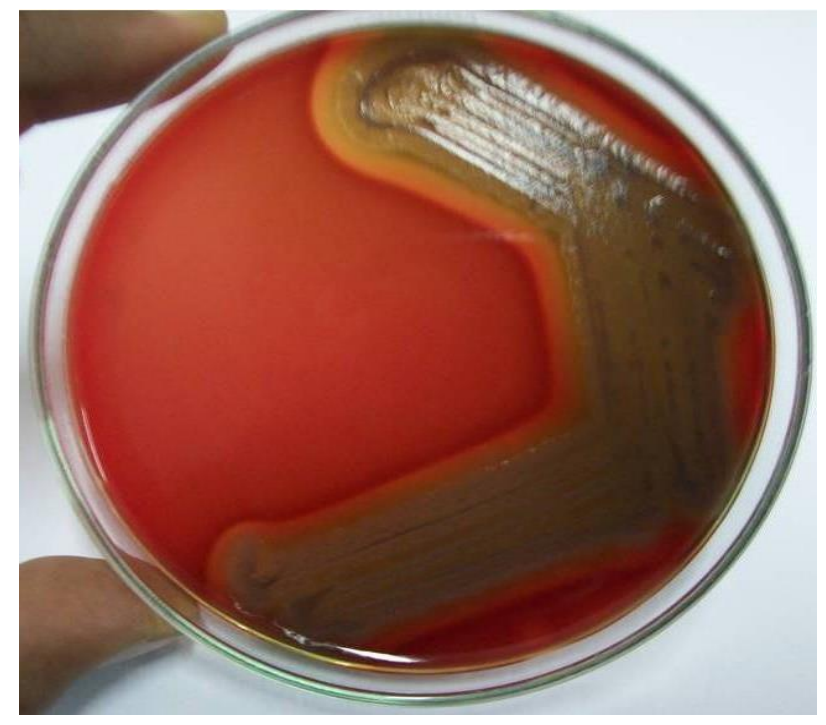

Figure 1: PB3A showing hemolytic colonies on Blood agar.

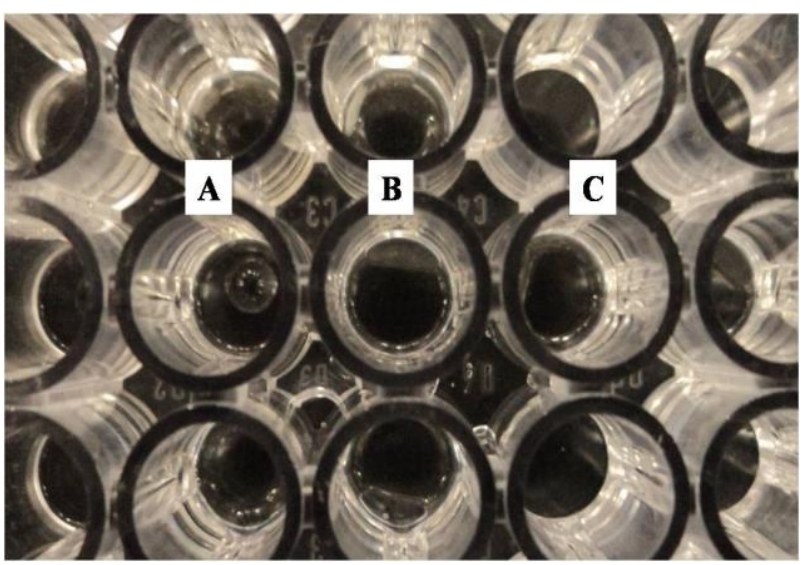

Figure 2: PB3A showing flat drop in $(C)$ in drop collapse test. A, Negative control; B, positive control.

Although the use hemolytic activity and drop collapse test constitute an easy method to screen biosurfactant production, determination of surface tension and emulsification activity (E24) was performed to confirm the biosurfactant producers (Plaza et al., 2011). Among the isolates, the strain PB3A reduced the surface tension of the culture medium up to $43 \mathrm{mN} / \mathrm{m}$ and also showed the highest emulsification index of about $65.5 \%$ against crude oil.

The efficient isolate PB3A was selected based on the results of screening tests and identified using partial sequence obtained from their 16S rRNA gene. The 16S rRNA sequences were aligned and showed that the isolate was Pseudomonas aeruginosa. The sequence PB3A showed high similarity of more than $97 \%$ with $P$. aeruginosa when compared with the other sequences existing in the GenBank using BLAST search. The 16S
rRNA sequence was then deposited in the GenBank database under the accession number of KF029593.1. The results of morphological and biochemical tests of the selected isolate PB3A is summarised in the Table 1. The isolate PB3A was motile, Gram negative bacilli and showed positive result for oxidase, citrate, urease and gelatine liquefaction and negative for other tests. The isolate was able to ferment mannitol, xylose and galactose. The results of the morphological and biochemical tests confirmed that the isolate PB3A was $P$. aeruginosa (Holt et al., 1994).

Table 1: Morphological and biochemical characteristics of the strain PB3A.

\begin{tabular}{ll}
\hline Tests & Results \\
\hline Gram stain & - \\
Motility & + \\
Oxidase & + \\
Catalase & - \\
Indole production & - \\
MR test & - \\
VP test & - \\
Citrate & + \\
$\mathrm{H}_{2} \mathrm{~S}$ & - \\
Gelatin liquefaction & + \\
Mannitol fermentation & + \\
Glucose fermentation & - \\
Xylose fermentation & + \\
Maltose fermentation & - \\
Galactose fermentation & + \\
Lactose fermentation & - \\
Sucrose fermentation & - \\
Nitrate reduction & - \\
Urea hydrolysis & + \\
\hline
\end{tabular}

The carbon source present in the production medium influences the bio surfactant production (Davis et al., 1999; Adamczak and Bednarsk 2000). Patel and Desai (1997) used whey wastes from dairy industries for the microbial growth and biosurfactant production at commercial scale against synthetic medium. Youssef et al. (2004) also screened for various substrates such as brewery effluents, molasses and fruit and vegetable decoction for production of biosurfactants using Bacillus strains.

The biosurfactant production depends upon the type of carbon substrate present in the production medium (Davis et al., 1999). In the present study, the various agro-industrial wastes were used as carbon sources for the biosurfactant production. Different waste substrates such as used castor oil, coconut oil, corn oil, motor oil, olive oil, olein, rapeseed oil, sunflower oil, barley bran, cassava flour waste, peanut cake, potato waste, rice bran and wheat bran were used as alternative source for carbon in the biosurfactant production medium. Among the cheap substrates used corn oil and cassava flour waste shows the maximum biosurfactant production of 


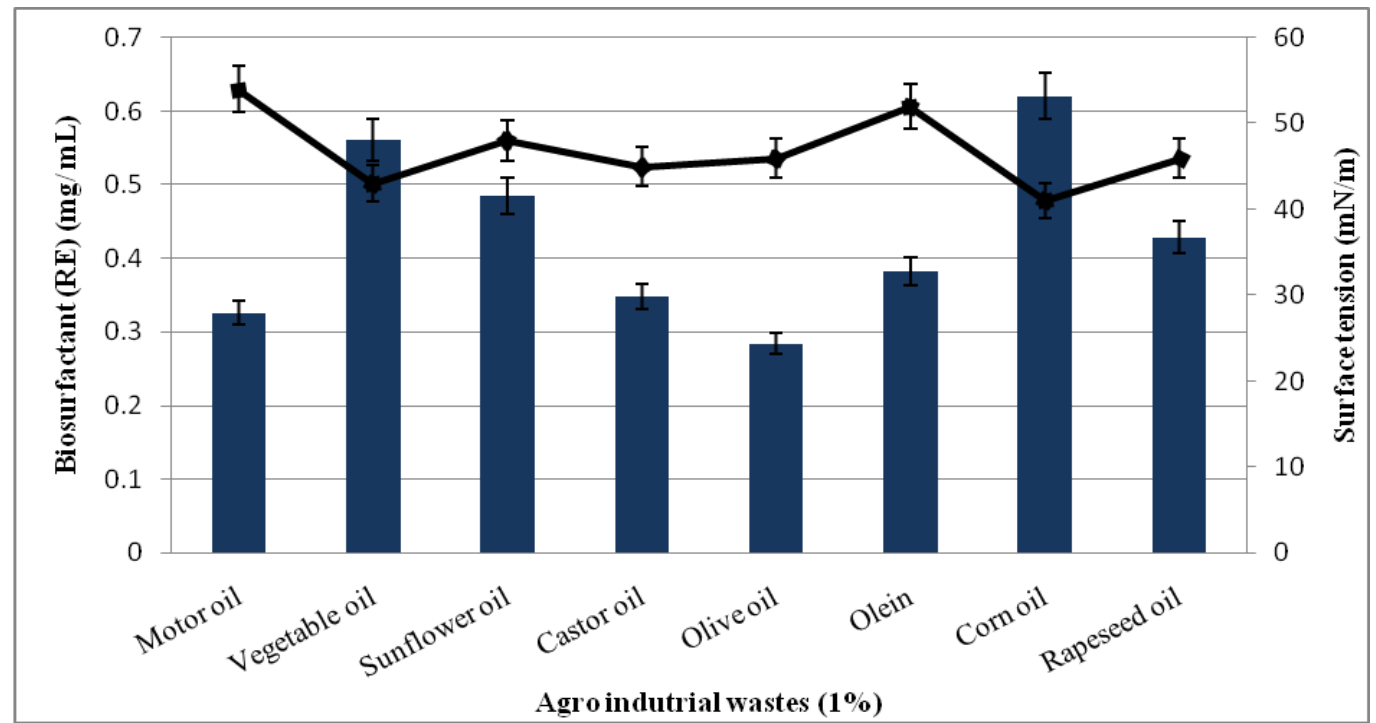

Figure 3: Effect of agro-industrial cheap substrates (used oils) on biosurfactant production.

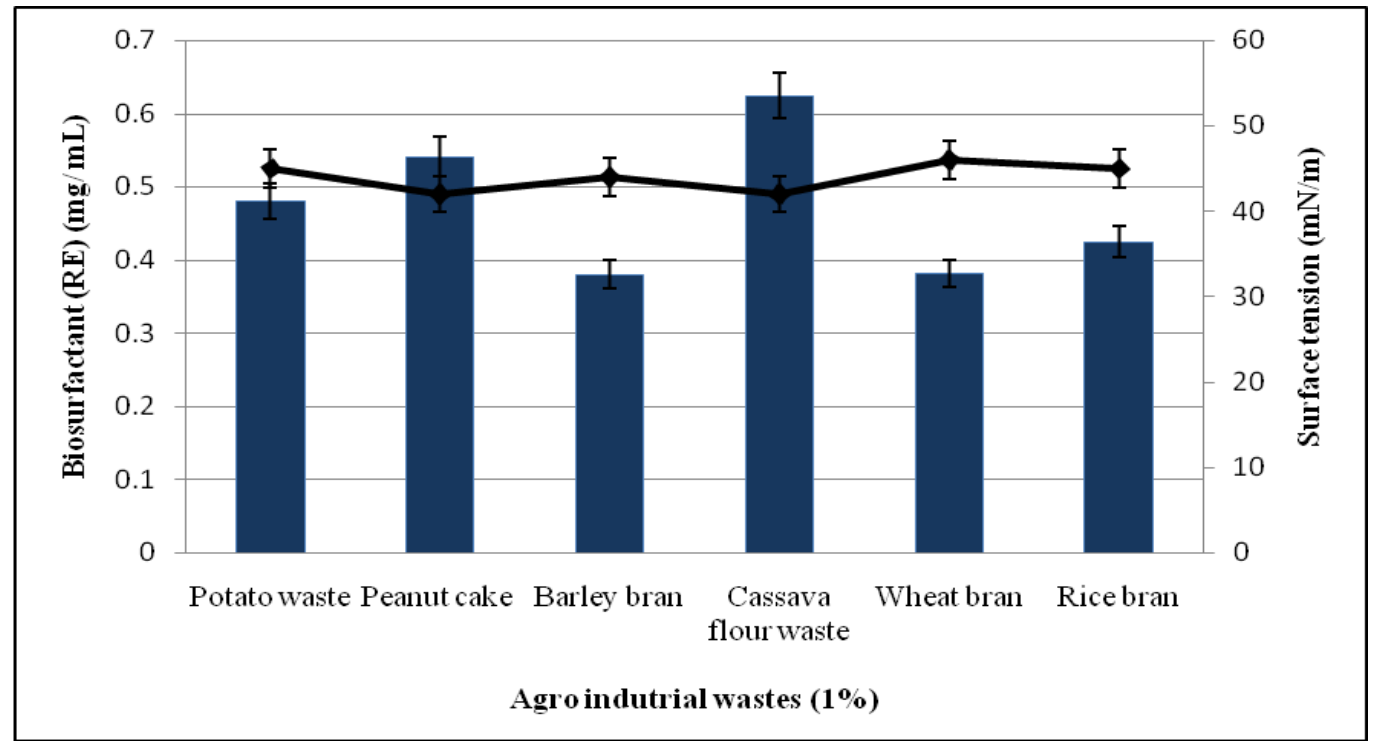

Figure 4: Effect of agro-industrial cheap substrates (solid wastes) on biosurfactant production.

Similarly surface tension values of the used corn oil and cassava flour waste amended medium after $48 \mathrm{~h}$ showed $41 \mathrm{mN} / \mathrm{m}$ and $42 \mathrm{mN} / \mathrm{m}$ respectively which were similar to the study conducted by Patel and Desai (1997) and Dubey and Juwarkar (2004). Among the cheap substrates, used Castor oil, motor oil, olive oil, olein, and wheat bran showed lower amount of biosurfactant production ranging from $0.28 \mathrm{mg} / \mathrm{mL}$ to $0.38 \mathrm{mg} / \mathrm{mL}$ compared to coconut oil, rapeseed oil, sunflower oil, barley bran, potato waste, peanut cake and rice bran which showed significant production ranging from 0.42 $\mathrm{mg} / \mathrm{ml}$ to $0.56 \mathrm{mg} / \mathrm{mL}$. Sheppard and Mulligan (1987) studied the utilization of peat hydrolyzate for the production of biosurfactant production and Mercadé et al., (1993) along with his co-workers also reported application of olive oil mill effluent for production of rhamnolipid by Pseudomonas sp. Manersa et al. (1991) studied the production of rhamnolipids by $P$. aeruginosa using olive oil as the carbon source in the production medium. Similar studies were also reported by Rashedi et al. (2006) and Raza et al. (2007) who have utilized molasses as a cheap carbon substrate for the production of biosurfactant. The present work on the application of 
cheap substrate for the biosurfactant production was in agreement with the other studies reported in the literature.

\section{CONCLUSION}

The present study deals with application of industrial wastes as substrates for the biosurfactant production. Efforts have been made to use different cheap substrates such as used oil and solid wastes for bio surfactant production. This approach would be economic in developing new strategies to increase the volume of productivity. Among the waste cooking oils corn oil and in case of solid wastes, cassava waste flour were suitable substrates for biosurfactant production using $P$. aeruginosa PB3A, a strain isolated from oil contaminated soils. Further optimization and production strategy have to be studied for the culture medium to increase the productivity of biosurfactant. However, further research is needed to develop biotechnological processes for increase productivity using complex wastes with nutritional potential for biosurfactant production.

\section{ACKNOWLEDGEMENT}

The authors are thankful to the Management, A.V.V.M. Sri Pushpam College for their grateful support and encouragement for the completion of work.

\section{REFERENCES}

Adamczak, M. and Bednarski, W. (2000). Influence of medium composition and aeration on the synthesis of biosurfactants produced by Candida antarctica. Biotechnology Letters 22(4), 313-316.

Ahimou, F., Jacques, P. and Deleu, M. (2000). Surfactin and iturin A effects on Bacillus subtilis surface hydrophobicity. Enzyme and Microbial Technology 27(10), 749-754.

Altschul, S. F., Gish, W., Miller, W., Myers, E.W. and Lipman, D. J. (1990). Basic local alignment search tool. Journal of Molecular Biology 215, 403-410.

Ausubel, F. M., Brent, R., Kingston, R. E., Moore, D. D., Seidman, J. G., Smith, J. A. and Strahl, K. (1994). Current Protocols in Molecular Biology. Greene Publishing Associates and Wiley-Interscience, New York.

Bodour, A. and Miller-Maier, R. M. (1998). Application of a modified drop collapse technique for surfactant quantification and screening of biosurfactantproducing microorganisms. Journal of Microbiological Methods 32(3), 273-280.

Bodour, A. A., Gerrero-Barajas, C. and Maier, M. (2004). Structure and characterization of flavolipids, a novel class of biosurfactants produced by Flavolipid sp. strain MTN11. Applied and Environmental Microbiology 10(6), 1114-1120.

Carrillo, P. G., Mardaraz, C., Pitta-Alvarez, I. S. and Giulietti, A. M. (1996). Isolation and selection of biosurfactant-producing bacteria. World Journal of Microbiology and Biotechnology 12(1), 82-84.
Cooper, D. G. and Goldenberg, B. G. (1987). Surfaceactive agents from two Bacillus species. Applied Microbiology and Biotechnology 53(2), 224-229.

Daverey, A. and Pakshirajan, K. (2009). Production, characterization, and properties of sophorolipids from the yeast Candida bombicola using a low-cost fermentative medium. Applied Biochemistry and Biotechnology 158(3), 663-674.

Davis, D. A., Lynch, H. C. and Varely, J. (1999). The production of surfactin in batch culture by Bacillus subtilis ATCC 21332 is strongly influenced by the condition of nitrogen metabolism. Enzyme and Microbial Technology 25(3), 322-329.

Desai, J. D. and Banat, I. M. (1997). Microbial production of surfactants and their commercial potential. Microbiology and Molecular Biology Reviews 61(1), 47-64.

Dubey, K. and Juwarkar, A. (2004). Determination of genetic basis for biosurfactant production in distillery and curd whey wastes utilizing Pseudomonas aeruginosa strain BS2. Indian Journal of Biotechnology 3(1), 74-81.

Holt, J. G., Krieg, N. R., Sneath, P. H. A., Staley, J. T. and Williams, T. (1994). Bergey's Manual of Determinative Bacteriology, $9^{\text {th }}$ edn. Williams \& Wilkins, Baltimore.

Jain, D. K., Collins-Thompson, D. L. and Lee, H. (1991). A drop collapsing test for screening biosurfactant-producing microorganisms. Journal of Microbiological Methods 13(4), 271-279.

Makkar, R. S. and Cameotra, S. S. (2002). An update on the use of unconventional substrates for biosurfactant production and their new applications. Applied Microbiology and Biotechnology 58(4), 428434.

Manersa, A., Bastida, J., Mercede, M. E., de Andres, C., Epsuny M. J. and Guinea, J. (1991). Kinetic studies on surfactant production by Pseudomonas aeruginosa 44T1. Journal of Industrial Microbiology 8(2), 133-136.

Marchesi, J. R., Sato, T., Weightman, A. J., Martin, T. A., Fry, J. C., Hiom, S. J. and Wade, W. G. (1998). Design and valuation of useful bacterium specific PCR primers that amplify genes coding for bacterial $16 \mathrm{~S}$ rDNA. Applied and Environmental Microbiology 64(2), 795-799.

Mercadé, M. E., Manresa, M. A., Robert, M., Epsuny, M. J., de Andres C. and Guinea, J. (1993). Olive Oil Mill Effluent (OOME). New substrate for biosurfactant production. Bioresource Technology 43(1), 1-6.

Mulligan, C. N., Cooper, D. G. and Neufeld, R. J. (1984). Selection of microbes producing biosurfactants in media without hydrocarbons. Journal of Fermentation Technology 62(4), 311-314.

Nitschke, M., Costa, S. G. and Contiero, J. (2005). Rhamnolipid surfactants: An update on the general aspects of these remarkable biomolecules. Biotechnology Progress 21(6), 1593-1600. 
Patel, R. M. and Desai, A. J. (1997). Biosurfactant production by Pseudomonas aeruginosa GS3 from molasses. Letters in Applied Microbiology 25(2), 9194.

Płaza, G. A., Pacwa-Płociniczak, M., Piotrowska-Seget, Z., Jangid, K. and Wilk, K. A. (2011). Agroindustrial wastes as unconventional substrates for growing of Bacillus strains and production of biosurfactant. Environment Protection Engineering 37(3), 63-71.

Prantera, M. T., Drowzdowicz, A., Leite, S. G. F. and Rosado, A. S. (2002). Degrading of gasoline aromatic hydrocarbons by two $\mathrm{N}_{2}$-fixing soil bacteria. Biotechnology Letters 24(1), 85-89.

Rashedi, H., Mazaheri Assadi, M., Jamshidi, E. and Bonakdarpour, B. (2006). Production of rhamnolipids by Pseudomonas aeruginosa growing on carbon sources. International Journal of Environmental Science and Technology 3(3), 297303.

Raza, Z. A., Khan, M. S. and Khalid, Z. M. (2007). Evaluation of distant carbon sources in biosurfactant production by a gamma ray-induced Pseudomonas putida mutant. Process Biochemistry 42(4), 686-692.

Rodrigues, L., Banat, I. M., Teixeira, J. and Oliveira, R. (2006). Biosurfactants: Potential applications in medicine. Journal of Antimicrobial Chemotherapy 57(4), 609-618.

Rodrigues, L. R. and Teixeira, J. A. (2008). Biosurfactants production from cheese whey. In: Advances in Cheese Whey Utilization. Cerd'an, M. E., Gonz'alez-Siso, M. and Becerra, M. (eds.). Transworld Research Network. pp. 81-104.

Ron, E. Z. and Rosenberg, E. (2001). Natural roles of biosurfactants. Environmental Microbiology 3(4), 229-236.

Saravanan, V. and Vijayakumar, S. (2012). Isolation and screening of biosurfactant producing microorganisms from oil contaminated soil. Journal of Academia and Industrial Research 1(5), 264-268.

Satpute, S. K., Bhawsar, B. D., Dhakephalkar, P. K. and Chopade, B. A. (2008) Assessment of different screening methods for selecting biosurfactant producing marine bacteria. Indian Journal of Marine Sciences 37(3), 243-250.

Sheppard, J. D. and Mulligan, C. N. (1987). The production of surfactin by Bacillus subtilis grown on peat hydrolysate. Applied Microbiology and Biotechnology 27(2), 110-116.

Singh, A., Van Hamme, J. D. and Ward, O. P. (2007). Surfactants in microbiology and biotechnology: Part 2. Application aspects. Biotechnology Advances 25(1), 99-121.

Singh, P. and Cameotra, S. S. (2004). Potential applications of microbial surfactants in biomedical sciences. Trends in Biotechnology 22(3), 142-146.

Tahzibi, A., Kamal, F. and Assadi, M. M. (2004). Improved production of rhamnolipids by a Pseudomonas aeruginosa mutant. Iranian Biomedical Journal 8(1), 25-31.
Tuleva, B. K., Ivanov, G. R. and Christova, N. E. (2002). Biosurfactant production by a new Pseudomonas putida strain. Zeitschrift fur Naturforschung C 57(34), 356-360.

Van Hamme, J. D., Singh, A. and Ward, O. P. (2006). Physiological aspects. Part 1 in a series of papers devoted to surfactants in microbiology and biotechnology. Biotechnology Advances 24(6), 604620.

Youssef, N. H., Duncan, K. E., Nagle, D. P, Sava, K. N., Knapp, R. M. and Mclnerney, M. J. (2004). Comparison of methods to detect biosurfactant production by diverse microorganisms. Journal of Microbiological Methods 56(3), 339-347. 